\title{
Paediatric home care in the 1990s
}

\author{
D Lessing, M A Tatman
}

Home care is not a new concept. Before the emergence of scientific medicine the rich were cared for at home by their physicians, and hospitals originated as charitable institutions in which the destitute, as much as the sick, were cared for.

A shift in the emphasis of hospital work from the social to the scientific began before the industrial revolution, and has accelerated during the era of the NHS. The expansion of medical technology has made the hospital a place for the application of rapid and sophisticated methods of medical management to the acutely ill. Priorities are efficiency, cost effectiveness, and fast turnover of patients. Though lengths of stay have been reduced, admission rates have risen. ${ }^{1}$ In inner city areas hospitals have become sources of primary care for their catchment populations, thereby usurping the role of the general practitioner. ${ }^{2}$ It is against this background that home care has developed.

\section{Emergence of home care in Britain}

In October 1989 the King's Fund produced a document entitled Hospital at Home: The Coming Revolution, ${ }^{3}$ which highlighted the increasing attention being paid to the concept of caring for seriously ill people at home by offering them intensive domiciliary support to avoid admission to hospital or at least to keep their stay as short as possible. Various factors may be responsible for this revival including the high cost of inpatient hospital care, the development of new techniques that make sophisticated home care feasible, patients' preference for home services, and the belief that outcomes may be improved by home nursing. Many 'hospital at home' schemes have been particularly concerned with the requirements of the elderly but paediatric schemes are now becoming more widely accepted.

The first paediatric schemes to be set up were in Rotherham in 1948, ${ }^{4}$ and in Birmingham in $1954 . .^{5}$ In the same year a home care service involving paediatricians as well as children's nurses was set up based at St Mary's Hospital, London. ${ }^{6}$

For more than 20 years there was little development of paediatric home care schemes; there were five such schemes in Britain in $\mathbf{1 9 7 0}$ and seven in 1980 , yet by 1988 there were 28 general home care schemes in operation ${ }^{7}$ and in 1991 there are 46, together with 30 specialist schemes. ${ }^{8}$ The specialist schemes care for neonates and children with specific conditions such as cancer and diabetes.

Home care in the United States

In the United States, cost containment and the system of prospective payment for hospital care based on diagnosis related groups has resulted in a strong incentive for hospitals to discharge their patients 'quicker and sicker'. 9 This has created an enormous demand for home health care. Services provided for children include apnoea monitoring, parenteral nutrition, intravenous medication, chemotherapy, and respiratory treatment. ${ }^{10}$

Home care is big business in the United States, and the increasing availability of technology designed to be used in the home both facilitates the work of home care and provides a commodity for the market. Despite the absence of any proof that apnoea monitoring reduces the risk of sudden infant death, sales of apnoea monitors reached $\$ 15$ million in $1988 .^{10}$

\section{Functions of home care}

The services of a home care team include:

- Direct services such as changing dressings, giving drugs including chemotherapy, tracheostomy care, general nursing care, and counselling.

- Monitoring of the patient and the effects of treatment by physical examination and the obtaining of laboratory specimens.

- Education of the family and patient, teaching therapeutic programmes, and enabling parents to care for their children.

- Coordinating services with hospital, general practitioner, and community.

- Patient advocacy.

The home care team is therefore multidisciplinary. The core team at St Mary's consists of a paediatrician, nurses trained in paediatrics, and a part time social worker. Physiotherapists and child psychiatrists are available to treat selected cases.

Children who particularly benefit from a home care programme are those with complex problems who need a coordinated multidisciplinary approach, those whose condition has not been stabilised in hospital, and children who are at risk in a hospital environment such as those who are immunocompromised. The burden placed on the families of such children may be minimised by regular and supportive home visiting.

The role of a home care team is to enable parents to take increasing responsibility for the care of their children and to be able to initiate services when required. Home visits may initially be frequent, but as the parents gain confidence the number of visits can be reduced. Many families seem more receptive to care and education when it is provided at home, and repeated visiting permits teaching of the care of the child in the context of daily needs. Home visiting seems to build up trust between the family and professional by reducing barriers that may be present in hospital. Dealing with

\author{
M A Tatman \\ Correspondence to: \\ Dr Lessing. \\ Child Health \\ Department of \\ Paediatric Epidemiology, \\ Institute of Child Health,
}


children in a family requires recognition that the paediatrician does not have ultimate control.

Home care in the new health service The changes currently taking place in the health service are of direct importance to home care.

The 'purchaser' function of the district health authority will mean that there is a shift from the management of services to assessment of how best to meet the health needs of their populations. $^{11}$

One of the principal effects of this is to bring to light the existing competition for funding between service providers all of whom are now contractors. This is not only between alternative sources of the same service, but also among the different elements of the health service that exist within a district.

Paediatric home care is likely to be competing for funding with health visiting and district nursing within a community services budget that is itself competing with the acute unit. The information that is most needed by the district health authority will therefore concern the extent to which home care can compete with acute paediatric care and other children's services for the workload. In particular, estimates of inpatient days saved and reductions in costs will be important.

Furthermore, fund holding general practitioners may wish to manage children themselves at home with the help of home care nurses, rather than refer them for hospital admission.

There will be a need for the responsibilities of home care to be clarified together with those of the general practitioner and the hospital paediatrician. Who should be responsible for assessing a child who has been discharged from hospital and then deteriorates at home?

\section{Importance of evaluation}

It is possible that increasing financial constraints on the health service may lead to children being discharged earlier from hospital. This will create an increasing demand for home care services. It is therefore important to gather information about the costs and effects of such services and the burdens that they may impose on the family caring for the child.

The objectives of home care services must be clearly defined in such a way that they may be measured. A service with objectives that are hard to measure is vulnerable to competition for funding from services which provide easily quantifiable outputs. The surgical specialties can readily provide information on their inputs and outputs from waiting lists and records of operations carried out. Such information has a strong influence on decision making, though it may not be a valid measure of need or of outcome.

Evaluation must therefore consider the following questions:

- How many children can be kept at home instead of being admitted to hospital?

- Can children be discharged earlier than would otherwise have been feasible?
- What are the comparative costs of home care and of keeping children in hospital?

- Is consumer satisfaction increased?

Donabedian stated that 'achieving and producing health and satisfaction, as defined for its individual members by a particular society or subculture, is the ultimate validator of quality of care'. ${ }^{12}$ Studies of consumer satisfaction with medical care have become an important component of health service research. Consumers are becoming more demanding about the type of care they receive and providers are becoming more attentive to their concerns. The district health authorities will be expected to carry out surveys to find out what patients, general practitioners, and the community think of the quality of services provided. ${ }^{11}$

Not only is patient satisfaction an integral part of quality of care, but patients who are more satisfied and hence more concerned in their own care will be more likely to comply with treatment regimens and may thus have better outcomes. ${ }^{13}$

\section{Approaches to evaluation of home care}

The scheme was set up in Rotherham because of a high infant mortality rate that was thought to be the result of cross infection in hospital. ${ }^{3}$ After three years the infant mortality rate had been halved. This might, however, be explained by other factors.

In a study carried out in the Bronx, children with chronic disorders were randomised to receive either home care or standard care. ${ }^{14}$ Interviews were carried out before and six months and one year after the test. The findings were that the intervention group had significantly greater benefits in two and possibly three important areas: satisfaction with care, the child's psychological adjustment, and (possibly) the mother's mental health.

Mitchell et al described a randomised controlled trial of an educational programme at home. ${ }^{15}$ Children who had been discharged after admission to hospital for asthma were randomised into 'intervention' and 'control' groups. The intervention group were visited for six months by a nurse whose role was to teach and advise the family. A number of outcomes were examined including use of drugs, parental knowledge, and readmissions to hospital. The only difference was that there were more readmissions to hospital among children who had received the intervention.

A non-randomised controlled trial in Boston, compared home and hospital intravenous antibiotic treatment for infectious exacerbations of cystic fibrosis. ${ }^{16}$ There were no significant differences in the rate of recovery of respiratory function in either group. Charges billed to the home care group were $60 \%$ of those for hospital care. This was a simple method for estimating cost effectiveness-the cost of alternative ways of obtaining the same outcome. Costs of a service comprise direct costs such as money spent by patients and health services, and indirect costs such as lost earnings or time spent by relatives caring for the patient.

The money saved by earlier discharge from 
hospital is termed a marginal saving. The most expensive care is usually concentrated at the beginning of a hospital admission, so that the marginal saving is less than the average cost of an inpatient day. If expenditure on overheads is unchanged the marginal saving may be as little as $10 \%$ of the average cost. ${ }^{3}$

Even if marginal savings are small the freeing of beds by early discharge of children will enable a greater throughput of patients. Under the present system this is a disadvantage as it entails further expense. In the future hospitals will be paid for each case and the advantages of early discharge will be seen not in marginal savings, but in the extra income generated by providing more care with the same facilities. ${ }^{17}$

Paediatricians considering establishing a home care service will need to weigh the potential benefits against the cost. Bergman et al argued that 'a home care programme should not be looked upon as a means of saving existing hospital money, but rather as providing a new type of comprehensive service., ${ }^{18}$ There is a need for further evaluation to assess the costs and benefits of home care services.

In 1968 Shrand foresaw that home care would 'realise its full potential in providing a hospital without walls extending into the community'. ${ }^{19}$ In the 1990s home care will be increasingly important within the integrated child health services.

We thank the Medical Research Council for funding the Health Services Research Training Fellowship held by Dr Tatman.
1 Department of Health. Health and personal social services statistics for England: 1990 edition. London: HMSO, 1990:79 (table 4.4).

2 Rhodes G, Prashar U, Young K. Primary health care in the inner cities after Acheson. London: Policy Studies Institute. inner cities after

3 Taylor D. Hospital at home: the coming revolution. London: King's Fund Centre Communication Unit, 1989.

4 Gillet JA. Children's nursing unit. BMF 1954;i:684-5.

5 Smellie JM. Domiciliary nursing service for infants and children. $B M \mathcal{F}$ 1956;i(suppl):256.

6 Lightwood R, Brimblecombe FSW, Rheinhold JDL, et al. A London trial of home care for sick children. Lancet 1957;i: 313-7.

7 Whiting M. Community paediatric nursing in England in 1988 London: University of London, 1988. (MSc thesis.)

8 Royal College of Nursing. Directory of paediatric community Fox DM, Andersen KS, Benjamin AE, Dunatov LJ. Intensive home health care in the United States: financing as tive holo healt care in the United states. Anancing as Health Care 1987;3:561-73.

10 Koska MT. Home care kids. Hospitals 1989;63:5 Jan:44-5

11 Department of Health. Working for patients: developin districts. London: HMSO, 1990:para 1.2.

12 Donabedian A. Evaluating the quality of medical care. Milbank Memorial Fund Quarterly; Health and Society 1966;
(19. 44:166-203.

13 Svarstad BL, Greenfield S, Kaplan S, et al. Expanding patient involvement in care: effects on patient outcomes. Ann Intern Med 1985;107:520-8.

14 Stein RK, Jessop DJ. Does pediatric home care make difference for children with chronic illness? Pediatrics 1984; 73:845-53.

15 Mitchell EA, Ferguson V, Norwood M. Asthma education by community child health nurses. Arch Dis Child 1986;61: 1184-9.

16 Donati MA, Guenette G, Auerbach H. Prospective controlled study of home and hospital therapy of cystic fibrosis
pulmonary disease. $\mathcal{F}$ Pediatr 1987;111:28-33.

17 Morgan M, Beech R. Variations in lengths of stay and rates of day case surgery: implications for the efficiency of surgical management. $f$ Epidemiol Community Health 1990;44: managem.

18 Bergman AB, Shrand H, Oppe TE. A pediatric home care program in London-ten years experience. Pediatrics 1965 36:314-21

19 Shrand H. Organised home care programs. In: Green $M$, Haggerty RJ, eds. Ambulatory pediatrics. Philadelphia: WB Saunders, 1968:64.

Penicillin resistant meningococci

I have always felt uneasy about relying on penicillin alone in the treatment of meningitis even when Gram negative diplococci are reported early on. Most of my patients get chloramphenicol, or more recently a cephalosporin, added to the penicillin-the main reason being that it is not unknown for on. call bacteriology to be wrong and in meningitis you don't take chances. Recent evidence about the emergence of strains of Neisseria meningitidis relatively resistant to penicillin I feel add support to this policy. ${ }^{1-3}$

In Leeds an 18 year old man with meningococcal meningitis relapsed on day 5 of treatment with penicillin but recovered quickly on chloramphenicol. ${ }^{1}$

Penicillin insensitive meningococci have been reported from Spain, Britain, South Africa, and most recently from Cananda. ${ }^{4} \mathrm{~A}$ report from Manchester showed reduced susceptibility to penicillin to have been constant at about 3 or $4 \%$ of isolates between 1987 and 1989. In Toronto the figure was $2 \cdot 4 \%$ in 1989 and $7 \cdot 4 \%$ in $1990 .^{4}$

Obviously we can no longer rely on $N$ meningitidis being fully sensitive to penicillin. Either higher doses of penicillin or an alternative antibiotic may be needed. 'Belt and braces' is not a bad principle in the treatment of meningitis, at least initially.

ARCHIVIST

1 Turner PC, Southern KW, Spencer NJB, Pullen H. Treatment failure in meningococcal meningitis. Lancet 1990;335:732-3.

2 Jones DM, Sutcliffe EM. Meningococci with reduced susceptibility to penicillin. Lancet 1990;335:863-4.

3 Saez Nieto JA, Vazquez JA, Marcos C. Meningococci moderately resistant to penicillin. Lancet 1990;336:54

4 Riley G, Brown S, Krishnan C. Penicillin resistance in Neisseria meningitidis. N Engl f Med 1991;324:997. 